\title{
S5ynthesis
}

International Scientific Conference of IT and Business-Related Research

\section{PROCENA UTICAJA DIGITALIZACIJE NA IZMENU STRUKTURE PAY TV TRŽIŠTA U REPUBLICI SRBIJI}

\author{
THE ASSESSMENT OF DIGITALIZATION IMPACT ON PAY TV MARKET \\ STRUCTURE IN THE REPUBLIC OF SERBIA
}

\author{
Marijana Vukašinović, Miroslav Mladenović \\ Telekom Srbija A.D., Beograd, Srbija
}

\begin{abstract}
Apstrakt:
Ovaj rad bavi se digitalizacijom kao jednom od najvećih i najznačajnijih promena koje će se desiti u bliskoj budućnosti u oblasti radiodifuzije i u oblasti elektronski komunikacija uopšte. Sa jedne strane daje se prikaz digitalizacije kao razvojnog procesa od nacionalnog značaja, a sa druge strane bavi se procenom mogućih scenarija pružanja usluge distribucije medijskih sadržaja u budućnosti i njihovim uticajem na strukturu domaćeg Pay TV tržišta. U radu su razmatrana dva moguća scenarija u skladu sa aktuelnim tržišnim okruženjem i poslovnim ambijentom. Cilj rada je da skrene pažnju svih sadašnjih i budućih učesnika pružaoca usluga u ovom tržišnom segmentu na moguće izazove koji ih u manjem ili većem obimu očekuju nakon uvođenja digitalizacije.
\end{abstract}

\section{Ključne reči:}

digitalizacija, Pay TV, multimedija, servisi, sadržaji, tržište.

\section{UVOD}

Na Regionalnoj konferenciji o radio-komunikacijama Međunarodne unije za telekomunikacije održanoj u maju i junu 2006. godine u Ženevi, predviđeno je uvođenje digitalne, i potpuno gašenje analogne televizije u Evropi najkasnije do 17. juna 2015. godine. Preporukom Evropske komisije, članicama Evropske unije je sugerisano da prekinu sa analognim emitovanjem i da potpuno pređu na digitalnu televiziju do početka 2012. godine. Republika Srbija se obavezala da će prelazak na digitalno emitovanje televizijskih programa i potpuno gašenje analognog servisa izvršiti do 17. juna 2015. godine.

Digitalizacija, odnosno prelazak sa analognog na digitalno emitovanje radio i televizijskog programa u Republici Srbiji ocenjuje se kao proces koji će dovesti do investicije u tehnologiju, razvoja i ekonomskog oporavka.

Imajući u vidu ovako visoka očekivanja od digitalizacije koja treba da dođu kao krajnji efekat pokretanja niza aktivnosti kako bi ce dostigli postavljeni ciljevi među kojima su i efikasnija i kvalitetnija isporuka televizijskih, radio, multimedijalnih i drugih znčajnih sadržaja do krajnjeg korisnika, nameće se potreba sagledavanja i procene budućih kretanja na domaćem Pay TV tržištu.

Ako se uzme u obzir činjenica da je digitalizacija zapravo najviše odnosi na korisnike krovne i sobne antene, a prema poslednjim istraživanjima njih je $38 \%$ od ukupnog potencijala domaćeg tržišta, nesumnjivo je da će u procesu digitalizacije najveći domaći Pay TV operatori uložiti značajan napor za dodatno tržišno pozicioniranje sa ciljem pridobijanja za sebe dela tržišta za sada nepokrivenog Pay TV servisima.

\section{Abstract:}

This paper considers digitalization as one of the greatest and most significant changes in the near future in broadcasting field and the field of electronic communications in the Republic of Serbia. It gives an overview of digitalization as development process of national importance, and estimates the impact of digitalization on domestic Pay TV market. Also, this paper considers two possible future scenarios in accordance with current market conditions and the business environment. The principal aim is to draw attention of all current and future market participants to possible challenges that may emerge upon the introduction of digitalization.

\section{Key words:}

digitalization, Pay TV, multimedia, services, content, market.

S obzirom na sveukupnu aktuelnu ekonomsku situaciju u zemlji i postavljene ciljeve digitalizacije, jedan od ključnih izazova i realnih potreba operatora koji trenutno posluju na domaćem tržištu u narednom periodu biće iznalaženje optimalnih poslovnih modela koji će u budućem izmenjenom poslovnom ambijentu obezbediti ne samo njihov razvoj kroz dodatno pozicioniranje u procesu digitalizacije nego i očuvanje postojećih korisničkih baza.

Sveukupni faktori koji karakterišu potencijal domaćeg tržišta i sve očekivane promene na istom u i nakon procesa digitalizacije pred domaće operatore postavljaju mnogo složenije zadatke od onih sa kojima se suočavaju operatori koji posluju u ekonomski razvijenijim zemljama.

\section{REZULTATI I DISKUSIJA}

\section{Digitalizacija - pojam, ciljevi i očekivani efekti}

Pod pojmom digitalizacije podrazumevamo proces predstavljanja teksta, fotografije, TV slike, zvuka, trodimenzionalnog objekta $\mathrm{u}$ formi elektronskog (digitalnog) zapisa, tj. pretvaranje analognog zapisa u digitalnu formu, pri tom ne gubeći informacije u transformisanju. Vrši se sa ciljem stvaranja oblika informacija sa kojim kompjuter zna raditi, organizovati i prerađivati ga, odnosno stvaranje oblika informacije koji se može lako obrađivati.

Zahvaljujući digitalizaciji koja omogućava lakše korišćenje, obradu, čuvanje i razmenu digitalizovanih podataka svake vrste (muzike, slike, filmova, knjiga i dr.), došlo je do revolucije 
u razvoju informacionih i komunikacionih tehnologija sto je doprinelo i ubrzanom razvoju digitalne televizije.

Nijedna etapa u dosadašnjem razvoju radija i televizije (prelazak sa mono na stereo zvuk ili sa crno-bele na TV u boji) nije napravila revoluciju kao digitalna TV koja sa sobom donosi mnoge prednosti i otvara put novim mogućnostima. Digitalno emitovana TV slika i ton su znatno otporniji na razne smetnje kojima su izloženi na putu od TV studija do kućnog prijemnika (atmoferske prilike, mehaničke barijere, industrija). Čak i veoma oštećen (degradiran) digitalni TV signal, odgovarajući TV prijemnik može da obradi i rekonstruiše. Time se uprkos uticajima smetnji, dobijaju visoko kvalitetni slika i zvuk na TV prijemniku. Dosadašnje emitovanje (analogno) podrazumevalo je: jedan TV kanal = jedan TV program, Dok digitalna televizija omogućava mnogo efikasnije korišćenje kapaciteta jednog TV kanala: jedan TV kanal = više TV programa. Zahvaljujući komprimovanju, digitalana TV omogućava da se na jednom kanalu emituje više raličitih TV programa, neki u visokoj HD, a neki u standardnoj SD rezoluciji. Pri tom je isti program moguće emitovati na više jezika, a da gledalac bira jezik ili prevod koji mu odgovara. Digitalizacija TV donosi mnogo širu društvenu korist i pruža prednosti koje daleko prevazilaze bolji prijem i kvalitetniju sliku i ton a koje obuhvataju: prilagođavanja sadržaja prema potrebama različitih ciljnih grupa, interaktivnost, kao i mogućnost pružanja usluga na zahtev, niže troškove emitovanja, itd.

$\mathrm{Na}$ osnovu navedenog može se zaključiti da su prednosti digitalne televizije višestruke. Korisnicima će digitalizacija omogućiti bolji kvalitet zvuka i slike, raznovrsniji sadržaj, više radio i televizijskih programa, nove usluge za osobe sa invaliditetom i za starije osobe, unapređene dodatne usluge, portabl i mobilni prijem programa, kao i konvergenciju usluga.

U Srbiji je predviđeno da se isključivanje analognog signala i prelazak na digitalno emitovanje TV programa sprovodi po fazama. Razlog za ovaj način prelaska na digitalno emitovanje uslovljen je veoma komplikovanom i složenom mrežom zemaljskih predajnika i zahteva angažovanje mnogih aktera, počev od Vlade, preko regulatornih tela, operatera, industrije i trgovaca, pa sve do građana. Osnovni problem predstavlja činjenica da ne postoji kompatibilnost između opreme za prijem analognog i digitalnog TV signala.

Plan prelaska na digitalno emitovanje će definisati rok od najviše šest meseci za potpuni prelazak sa analognog na digitalno emitovanje u svakom od prethodno određenih regiona. Vlada će obavestiti javnost najmanje devet meseci pre potpunog isključenja analognog signala u svakom od regiona.

Na teritoriji Republike Srbije moguće je planirati nekoliko mreža s nacionalnom pokrivenošću. Svaka mreža imaće odgovarajući multipleks. Dva multipleksa biće puštena u rad i popunjena tokom procesa prelaska u skladu s principima navedenim u daljem tekstu. Dodatni multipleksi biće pušteni u rad i popunjeni nakon prelaska pod uslovom da postoji tržišna potreba $i$ da je to finansijski izvodljivo.

Multipleksi će se popunjavati programima koji se emituju u skladu sa zakonom koji uređuje oblast radiodifuzije, odnosno na osnovu dozvola za zemaljsko emitovanje koje je izdao RRA, uz poštovanje sledećih principa:

- programi javnog radiodifuznog servisa i imalaca dozvole za emitovanje televizijskog programa sa nacionalnim pokrivanjem nalaziće se $\mathrm{u}$ istom multipleksu;

- servisne zone iz postojećih dozvola za analogno emitovanje neće biti smanjene;

- protok podataka unutar multipleksa iznosi najmanje $2 \mathrm{Mb} / \mathrm{s}$ po pojedinačnom televizijskom programu koji se emituje u standardnoj rezoluciji (SDTV) i $5 \mathrm{Mb} / \mathrm{s}$ u visokoj rezoluciji (HDTV) u varijanti kodovanja sa konstantnim protokom, odnosno protok je obezbeđen korišćenjem odgovarajućeg statističkog multipleksera.

Dva multipleksa biće popunjena emiterima koji imaju dozvolu za nacionalno emitovanje i lokalnim, odnosno regionalnim kanalima koji imaju dozvolu izdatu od strane RRA za određene regije. Očekivani krajnji efekti digitalizacije sa aspekta pružaoca usluga su mogućnost prilagođavanja sadržaja prema potrebama različitih ciljnih grupa, interaktivnost, kao i mogućnost pružanja usluga na zahtev, niže troškove emitovanja i konvergenciju usluga. Državi će digitalizacija omogućiti efikasnije korišćenje radio-frekvencijskog spektra, upotrebu oslobođenog dela spektra za nove usluge, promociju razvoja tehnologije i nova radna mesta, unapređenu konkurenciju i više mogućnosti za unapređenje stvaralaštva i očuvanje kulturnog identiteta. Istovremeno, prelazak na digitalno emitovanje uvešće red u etru budući da će mesto u multipleksima biti omogućeno samo emiterima sa važećim dozvolama za emitovanje programa.

\section{Presek stanja Pay TV tržišta u Republici Srbiji}

Ekspanzija distribucije multimedijalnih sadržaja na domaćem tržištu započeta je pre 15-tak godina, masovnom pojavom kablovskih sistema distribucije sadržaja, praćene satelitskom distribucijom, organizovanim ulaskom na tržište svetskih brendova kada su u pitanju TV i radio kanali i masovnim priključenjem korisnika.

Prvih nekoliko godina razvoja tržišta u ovoj oblasti karakreriše visok stepen konkurentnosti, beskompromisna borba od strane većine operatora za zauzimanje tržišta, bez mnogo fer play-a i poštovanja pravila i moglo bi se reći pod parolom da cilj opravdava sredstva, što će odrediti odnos snaga koji je i danas manje - više nepromenjen kada je reč o domaćem tržištu distribucije multimedijalnih sadržaja.

Tek na polovini pomenutog petnaestogodišnjeg razvojnog perioda ova oblast se uvodi u ozbiljnije regulatorne okvire i danas je u svim važnijim segmentima regulisana, sa izuzetkom određenih oblasti za koje još uvek ne postoje adekvani mehanizmi i optimalna rešenja.

Prema zvaničnom izveštaju Republičke agencije za elektronske komunikacije (RATEL) za 2013. godinu u Srbiji postoje 94 registrovana operatora od kojih većina pruža usluge distribucije multimedijalnog sadržaja (RATEL, 2014). Najveći broj operatora usluge pruža putem KDS-a (Kablovsko Distributivni Sistem) koji ujedno pokrivaju i najveći deo tržišta, određeni deo tržišta pokriven je satelitskim distributivnim sistemima, sa primetnim porastom distribucije putem IPTV tehnologije.

Ponuda operatora uglavnom je bazirana na velikom broju televizijskih i radio kanala sa emitovanjem programa uživo, uz izuzetak nekoliko velikih operatora koji u ponudi imaju i specijalizovane tematske digitalne pakete (Pay TV) i servise tipa Video na zahtev, kao i objedinjene pakete usluga od strane operatora koji za to imaju tehničke mogućnosti. Cene usluga su uglavnom ujednačene bez obzira na primenjenu tehnologiju distribucije.

Tržišno učešće operatora po broju pretplatnika u 2013. godini prikazano je na sledećoj slici 1.

Prema izveštaju Ratel-a broj korisnika usluge distribucije multimedijalnih sadržaja u 2013. Godini iznosio je oko 1,55 miliona što je za 7,6\% više nego u 2012. godini. Penetracija Pay TV servisa je oko $62 \%$ u odnosu na ukupan broj domaćinstava u Srbiji (RATEL, 2014). 

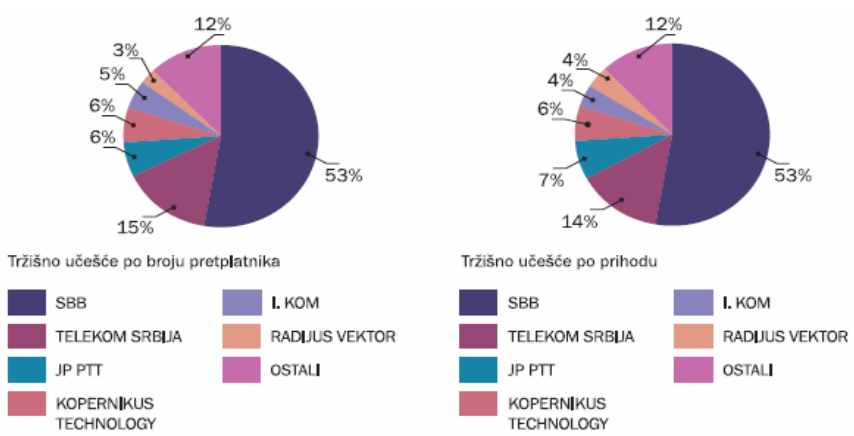

Slika 1. Tržišno učešće Pay TV operatora u 2013. godini

Prihod od usluga distribucije multimedijalnog sadržaja u 2013. godini iznosio je 13,2 milijarde što je za $6,7 \%$ više nego prethodne godine (RATEL, 2014). Rast prihoda prvenstveno je posledica stalnog povećanja broja korisnika, poboljšanja kvaliteta i uvođenja novih usluga, ali i kao posledica povećanja cene mesečne pretplate.

Imajući u vidu navedene podatke nesumnjivi zaključak je da se radi o ozbiljnom tržišnom segmentu sa respektabilnim brojem priključenih korisnika i još respektabilnijim prihodima koji se u ovoj oblasti ostvaruju.

Uzevši u obzir činjenicu da je dostignuta penetracija od $62 \%$ i da se nepokriveni segment tržišta uglavnom odnosi na ruralna područja u kojima za sada ne postoji tehnička mogućnost realizacije Pay TV servisa primenjenim tehnologijama, bilo da se radi o nemogućnosti pružanja servisa kroz postojeću infrastrukturu ili neisplativosti stvaranja tehničkih uslova kroz izgradnju potrebne infrastrukture $\mathrm{u}$ ovim područjima, $\mathrm{u}$ ovom trenutku prostor za rast $\mathrm{u}$ domenu prikjučenja novih korisnika je sve ma- nji, a posebno novih korisnika na kablovskoj inftastrukturi, bilo da se radi o KDS-u ili IPTV-u. Ako uključimo i sve druge relevantne tržišne faktore koji karakterišu kretanja u ovoj oblasti dolazi se do zaključka da je tržište distribucije multimedijalnih sadržaja u svom sadašnjem obliku ušlo u početnu fazu zasićenja i da je glavni budući izazov operatora zapravo zadržavanje postojećih korisnika, iznalaženje modela za privlačenje korisnika sa konkurentskih mreža, kao i modela za pridobijanje korisnika iz za sada nepokrivenog segmenta tržišta.

\section{Procena uticaja digitalizacije na izmenu Pay TV tržišta u Republici Srbiji}

U poslednjoj deceniji strukture lokalnih tržišta se dinamično menjaju usled stalnog tehnološkog napredka koji za posledicu ima konstantnu pojavu novih platformi za distribuciju multimedijalnih sadržaja do krajnjih korisnika, kao i pojavu novih učesnika - pružaoca usluga u ovom tržišnom segmentu. Svako tržište je različito i određeno je nizom faktora koji međusobno svojim uzročno posledičnim vezama određuju poslovni ambijrent i tržišna kretanja. Da bi se sagledao pravac u kome će se kretati domaće Pay TV tržište na koje će predstojeća digitalizacija nesumnjivo imati uticaj i da bi se bar okvirno utvrdio stepen uticaja digitalizacije na ovaj tržišni segment nakon uvođenja digitalizacije neophodno je izvrširti detaljne analize pažljivo odabranih parametara koji u najvećoj meri mogu dovesti do promena u tržišnoj strukturi. Procena uticaja digitalizacije na izmenu domaćeg Pay TV tržišta primenjena u ovom radu bazirana je na nekoliko osnovnih parametara:

Demografski podaci za Republiku Srbiju - ovi podaci su od izuzetne važnosti za procenu potencijalne izmene strukture Pay TV tržišta nakon digitalizacije imajući u vidu da je digitalizacija prvenstveno usmerena na deo tržišta, odnosno na domaćinstva koja u ovom trenutku primaju televizijski signal

\begin{tabular}{|c|c|c|}
\hline Broj stanovnika u RS po popisu od 2011. godine & $\begin{array}{c}\text { Procenat ruralnih domaćinstava u ukupnom broju } \\
\text { domaćinstava }\end{array}$ & Procenat ruralnih površina u ukupnoj teritoriji RS \\
\hline 7.182 .862 & 41,25 & 85 \\
\hline Ukupna površina teritorije RS $\left(\mathrm{km}^{2}\right)$ & Urbane površine $\left(\mathrm{km}^{2}\right)$ & Ruralne površine $\left(\mathrm{km}^{2}\right)$ \\
\hline 77474 & 11621,1 & 65852,9 \\
\hline Broj domaćinstava u RS & Broj domaćinstava u urbanim područjima RS & Broj domaćinstava u ruralnim područjima RS \\
\hline 2.497 .187 & $1.467 .097,36$ & $1.030 .089,64$ \\
\hline Broj domaćinstava po $\mathrm{km}^{2}$ & Broj domaćinstava u urbanim područjima po $\mathrm{km}^{2}$ & Broj domaćinstava u ruralnim područjima po km ${ }^{2}$ \\
\hline 32,23258125 & 126,2442766 & 15,64228208 \\
\hline
\end{tabular}

Tabela1. Demografski podaci za Republiku Srbiju prema Republičkom zavodu za statistiku:Ruralna domaćinstava i ruralna površina teritorije RS.

Izvor: http://webrzs.stat.gov.rs/WebSite/Public/PageView.aspx?pKey=162

\begin{tabular}{|c|c|c|c|c|c|c|c|}
\hline \multirow{2}{*}{\multicolumn{2}{|c|}{ Karakteristike stanovništva }} & \multicolumn{2}{|c|}{ Stopa aktivnosti } & \multicolumn{2}{|c|}{ Stopa zaposlenosti } & \multicolumn{2}{|c|}{ Stopa nezaposlenosti } \\
\hline & & \multirow{2}{*}{$\begin{array}{c}\text { urbano } \\
66,10\end{array}$} & \multirow{2}{*}{$\begin{array}{c}\text { ruralno } \\
73,10\end{array}$} & \multirow{2}{*}{$\begin{array}{c}\text { urbano } \\
54,30\end{array}$} & \multirow{2}{*}{$\begin{array}{c}\text { ruralno } \\
64,80 \\
\end{array}$} & \multirow{2}{*}{$\begin{array}{c}\text { urbano } \\
17,90\end{array}$} & \multirow{2}{*}{$\begin{array}{c}\text { ruralno } \\
11,30\end{array}$} \\
\hline & muškarci & & & & & & \\
\hline Pol & žene & 53,40 & 52,00 & 43,10 & 43,50 & 19,20 & 16,30 \\
\hline \multirow{3}{*}{ Obrazovanje } & niže & 29,60 & 51,30 & 20,60 & 46,40 & 30,40 & 9,60 \\
\hline & srednje & 63,10 & 70,30 & 50,40 & 59,20 & 20,10 & 15,80 \\
\hline & visoko i više & 80,00 & 77,70 & 72,00 & 68,30 & 10,00 & 12,10 \\
\hline \multirow{3}{*}{$\begin{array}{l}\text { Starosna } \\
\text { kategorija }\end{array}$} & $15-24$ & 25,30 & 32,70 & 14,60 & 19,90 & 42,00 & 39,20 \\
\hline & $25-49$ & 82,60 & 79,10 & 68,00 & 68,80 & 17,70 & 13,00 \\
\hline & $50-64$ & 45,00 & 56,60 & 38,60 & 52,70 & 14,20 & 7,00 \\
\hline
\end{tabular}

Tabela 2. Osnovni indikatori tržišta rada za urbano i ruralno stanovništvo u RS

Izvor: http://webrzs.stat.gov.rs/WebSite/Public/PageView.aspx?pKey=162 
preko kućne, odnosno sobne antene. U Tabeli 1 dati su osnovni demografski podaci koji određuju ukupan potencijal tržišta i ukazuju na osnovne razlike između urbanih i ruralnih područja u demografskom smislu. U Tabeli 2 prikazani su osnovni indikatori rada u urbanom i ruralnom području. Uporedna analiza ruralnog i urbanog stanovništva pokazuje da postoje velike razlike između ove dve populacije. Gotovo svi indikatori nivoa životnog standarda ukazuju na lošiji životni standard ruralnog stanovništva.

Ekonomski parametri će odigrati značajnu ulogu na izmenu strukture tržišta, jer sa jedne strane određuju kupovnu moć stanovništva, što direktno utiče na stepen tražnje za konkretnim proizvodima i uslugama pa i multimedijalnim uslugama, a sa druge strane određuju poslovni ambijent i uslove poslovanja svih privrednih subjekta uključujući i operatore. U sledećoj tabeli dati su neki od najvažnijih ekonomskih faktora.

\begin{tabular}{|l|l|}
\hline Stopa nezaposlenosti & $20,3 \%$ (septembar 2014) \\
\hline Prosečna potrošačka korpa & $66.068,71$ dinara (avgust 2014) \\
\hline Minimalna potrošačka korpa & $34.291,44$ dinara (avgust 2014) \\
\hline $\begin{array}{l}\text { Prosečna zarada bez poreza i } \\
\text { doprinosa }\end{array}$ & 45.610 dinara (avgust 2014) \\
\hline Osnovna korpa ikt usluga & $3,50 \%$ prosečne zarade \\
\hline Proširena korpa ikt usluga & $10,98 \%$ prosečne zarade \\
\hline
\end{tabular}

Tabela 3. Ekonomski parametri

Izvor: Ministarstvo trgovine, turizma i telekomunikacija

Način prijema radio i televizijskih programa na domaćem tržištu u ovom trenutku i u periodu do uvođenja digitalizacije u priličnoj meri imaće uticaj na izmenu strukture tržišta nakon digitalizacije. Za očekivati je da će u periodu neposredno pre digitalizacije kao i u periodu neposredno nakon uvođenja digitalizacije doći do ukrupnjavanja tržišta, da će se smanjiti broj kablovskih operatora koji uslugu pružaju primenom analogne tehnologije. Takođe je za očekivati da će zbog promena koje se u etru očekuju nakon uvođenja digitalizacije doći i do izmena strukture ponude Pay TV operatora. Trenutna raspodela načina distribucije, odnosno prijema radio i televizijskih programa na domaćem tržištu data je na sledećoj slici.

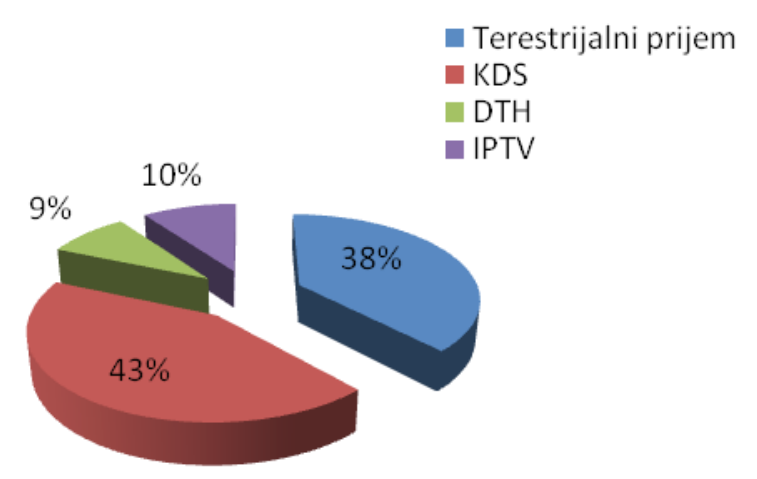

Slika 2. Raspodela načina prijema TV programa na domaćem tržištu

Parametri gledanosti televizijskih programa su možda i najrespektabilniji skup parametara od kojih će u velikoj meri zavisiti i buduća struktura tržišnog segmenta distribucije radio i televizijskih programa. Na osnovu istraživanja koje je sproveo AGB Nielsen Audience Measurement u aprilu 2014. godine, gle- danost nacionalnih emitera u Srbiji iznosi u proseku oko 204 minuta dnevno (AGB Nielsen, 2014). Na osnovu istog istraživanja utvrđeno je da je prosečno vreme praćenja televizije u Srbiji u aprilu iznosilo 5 sati i 20 minuta dnevno na osnovu čega dolazimo do podatka da je gledanost nacionalnih emitera u aprilu iznosila oko $60 \%$ od ukupnog vremena koje korisnici provode ispred TV ekrana.

Ukoliko se u obzir uzmu navedeni parametri kao i planirani postupak, dinamika i ciljevi buduće digitalizacije u izvesnoj meri može se doći do procene budućih tržišnih kretanja.

Imajući u vidu da plan prelaska na digitalno emitovanje predviđa rok od najviše šest meseci za potpuni prelazak sa analognog na digitalno emitovanje u ovom ne tako malom periodu očekuju se osetne promene tržišne strukture u ovom tržišnom segmentu. S obzirom na aktuelne ekonomske parametre kao i na podatke o učešću programa nacionalnih emitera u ukupnoj gledanosti svih televizijskih programa dostupnih korisniku vrlo je verovatno da će u šestomesečnom prelaznom periodu u određenoj meri doći do odliva Pay TV korisnika i njihovog prelaska digitalni terestrijani način prijema. Ovo se prvenstveno odnosi na korisnike koji primaju programe preko neke od raspoloživih tehnoligija - KDS, IPTV ili DTH. Procena navedenog pravca kretanja na Pay TV tržištu do kraja 2015. godine grafički je prikazana na Slici 2. Za određivanje stepena odliva broja korisnika sa Pay TV na digitalni terestrijalni prijem programa trebalo bi na relevantne parametre primeniti neku od poznatih matematičkih metoda i na takav način izvršiti prognozu stepena odliva što nije tema kojom se bavi ovaj rad.

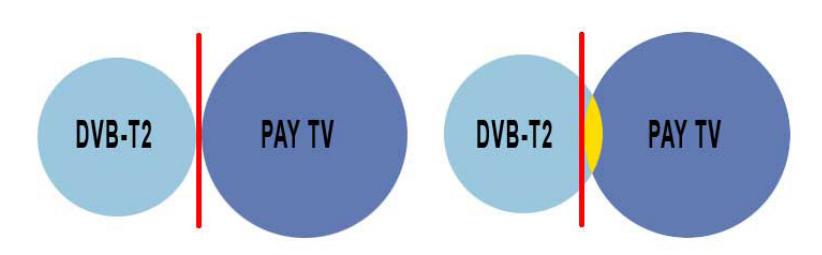

Slika 3. Grafički prikaz tržišnog kretanja do kraja 2015. godine

Nakon isteka šestomesečnog prelaznog perioda procena je da će se desiti prelomni trenuutak ukoliko se u tom momentu pusti u rad jedan ili više komercijalnih multipleksa koji će za $32 \%$ tržišta po prvi put omogućiti u punom obimu sve multimedijalne adržaje u okviru servisa i usluga koji će u većoj meri do tog momenta biti privilegija Pay TV korisnika. Dva su moguća scenarija uvođenja u eksploataciju komersijalnih multipleksa:

- Scenario 1

Osnovna pretpostavka ovog scenarija je da će se nakon prelaznog perioda, a u momentu pokretanja komercijalnih multipleksa Javno preduzeće Emisiona tehnika i veze pojaviti kao pružalac Pay TV servisa i na taj način ući u tržišnu utakmicu sa postojećim Pay TV operatorima. U slučaju da dođe do realizacije ovog scenarija trenutno aktivni Pay TV operatori bi u svakom slučaju bili onemogućeni da naprave upliv na do sada Pay TV servisom nepokvini tržišni segment, a u zavisnosti od strukture ponude i cenovne politike upliv bi se mogao dogoditi u obrnutom smeru.

- Scenario 2

Osnovna pretpostavka scenarija je da će nakon prelaznog perioda, a u momentu pokretanja komercijalnih multipleksa Javno preduzeće Emisiona tehnika i veze 
staviti na raspolaganje ove resurse pod jednakim uslovima Pay TV operatorima za plasiranje njihovih ponuda ka do sada Pay TV servisima nepokrivenom tržišnom segmentu. U kom pravcu bi se u slučaju realizacije ovog scenarija menjalo Pay TV tržište i kog obima bi bile potencijalne promene u ovom momentu teško je predvideti. Nesumnjivo je da i do promena došlo i da bi one svakako bile u značajnoj meri. Grafički prikaz pretpostavljenog Scenarija 1 i Scenarija 2 dat je na Slici 4.
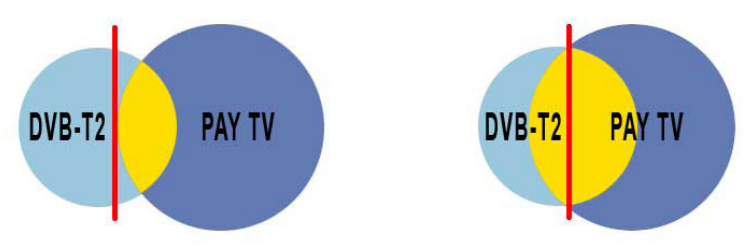

Slika 4. Grafički prikaz Scenarija 1 i Scenarija 2

\section{REZIME}

Prema Strategiji za prelazak sa analognog na digitalno emitovanje ratio i televizijskog programa građani će digitalizacijom dobiti bolji kvalitet zvuka i slike, raznovrsnije sadržaje, više radio i televizijskih programa, unapređene dodatne usluge kao i konvergenciju istih.

Pružaocima sadržaja će biti omogućeno prilagođavanje sadržaja prema potrebama ciljnih grupa, interaktivnost, mogućnost pružanja usluga na zahtev, niže troškove emitovanja kao i konvergenciju usluga. Državi će digitalizacija omogućiti efikasnije korišćenje radio-frekvencijskog spektra, upotrebu oslobođenog dela spektra za nove usluge, razvoj tehnologije i nova radna mesta, unapređenje konkurencije i uvođenje reda u etru. Ciljevi su visoki, aktivnosti su opsežne, a očekivanja su velika. Nakon 17. juna 2015. godine mnogo toga će se promeniti.

Obimom, kvalitetom i dinamikom pripremnih radnji za ovaj trenutak meriće se stepen ozbiljnosti tržišnih igrača merljivim rezultatom kroz njihovu buduću tržišnu poziciju. Od konkretnih aktivnosti svakoga od njih ponaosob i sposobnosti da se prilagode dolazećem tržišnom ambijentu zavisiće i stepen promena ovog tržišnog segmenta i obim izmene njegove strukture usled uvođenja digitalizacije.

\section{LITERATURA}

AGB Nielsen. (2014). Gledanost nacionalnih emitera u Srbiji. Preuzeto sa http://www.agbnielsen.net/whereweare/dynPage.asp?lang=local\&id=354\&country=Serbia

Radojičić, V., Bakmaz, B., Veličković, S. (2013). Prognoziranje novih telekomunikacionih servisa. Beograd: Saobraćajni fakultet.

RATEL. (2014). Pregled tržišta telekomunikacija u Republici Srbiji u 2013. godini. Preuzeto 12.03.2015. sa

http://www.ratel.rs/upload/documents/Pregled_trzista/ Ratel\%20Pregled\%20trzista\%202014.pdf

Republički zavod za statistiku. (2011). Popis stanovništva domaćinstava i satnova u Republici Srbiji. Preuzeto 12.03.2015 sa. http://webrzs.stat.gov.rs/WebSite/Public/PageView. aspx?pKey=162

RTS. (2014). Digitalizacija. Preuzeto 12.03.2015 sa http://www. rts.rs/page/rts/ci/Digitalizacija.html 